\title{
Polymerization-Induced Self-Assembly via RAFT-mediated Emulsion Polymerization of Methacrylic Monomers
}

\author{
Xiaocong Dai ${ }^{\mathrm{a}}$, Liangliang Yu ${ }^{\mathrm{a}}$, Yuxuan Zhang ${ }^{\mathrm{a}}$, Li Zhang ${ }^{\mathrm{a}, \mathrm{b}}$, Jianbo Tan $^{\text {a,b }}$ \\ a. Department of Polymeric Materials and Engineering, School of Materials and Energy, \\ Guangdong University of Technology, Guangzhou 510006, China. \\ b. Guangdong Provincial Key Laboratory of Functional Soft Condensed Matter, Guangzhou \\ 510006, China.
}

Xiaocong Dai and Liangliang Yu contributed equally to this work.

*Corresponding authors: tanjianbo@gdut.edu.cn 


\section{EXPERIMENTAL SECTION}

Materials. Glycidyl methacrylate (GlyMA, Aladdin), methyl methacrylate (MMA, Aladdin), and benzyl methacrylate (BzMA, Aladdin) were passed through a column of basic alumina (Aladdin) prior to storage under refrigeration at $4{ }^{\circ} \mathrm{C}$. Poly(ethylene glycol) methyl ether methacrylate (PEGMA, $\quad M_{\mathrm{n}}=500 \mathrm{~g} / \mathrm{mol}, \quad$ Sigma-Aldrich), dicyclohexylcarbodiimide (DCC, Aladdin), 4-dimethylaminopyridine (DMAP, Aladdin), and hydroquinone (Aladdin) were used as received. Azobisisobutyronitrile (AIBN, Aladdin) was recrystallized from ethanol prior to storage under refrigeration at $4{ }^{\circ} \mathrm{C}$. L-Ascorbic acid sodium salt (NaAs, 99\%) and potassium persulfate (KPS, Aladdin) were purchased from Aladdin. KPS was recrystallized from cold water. 4-Cyano-4-(dodecylsulfanylthiocarbonyl)sulfanylpentanoic acid (CDPA) was synthesized according to the literature. ${ }^{1}$ All monomers were passed through a column of $\mathrm{Al}_{2} \mathrm{O}_{3}$ to remove the inhibitor before use.

Characterization. Transmission electron microscopy (TEM). The obtained dispersions were diluted 100-fold with water. A drop of the solution was placed on a copper grid for 1 min and then blotted with filter paper to remove excess solution. A drop of uranyl acetate solution $(0.5 \mathrm{wt} \%)$ was soaked on the same copper grid for $1.5 \mathrm{~min}$, and then blotted with filter paper to remove excess strain. TEM observations were carried out on a Hitachi 7700 instrument operated at $120 \mathrm{kV}$.

Gel permeation chromatography (GPC). The molecular weight and polydispersity of the block copolymers were measured by gel permeation chromatography (GPC) at $35{ }^{\circ} \mathrm{C}$ using a Waters 1515 GPC instrument with tetrahydrofuran (THF) as the mobile phase and Waters styragel HR1 and HR4 columns. The flow rate of THF was $1.0 \mathrm{~mL} / \mathrm{min}$. Linear polystyrene polymers with narrow molecular weight distributions were used as the standards to calibrate apparatus.

${ }^{1}$ H NMR spectroscopy. Nuclear magnetic resonance (NMR) spectra were recorded in $\mathrm{CDCl}_{3}$ or DMSO- $d_{6}$ using a Bruker Avance III HD $400 \mathrm{MHz}$ NMR spectrometer at a temperature of $25^{\circ} \mathrm{C}$.

Differential scanning calorimetry (DSC). DSC was performed using a differential scanning calorimetric (DSC3 Mettler Toledo) instrument under a stream of nitrogen. The sample accurately weighed $(\approx 4 \mathrm{mg})$. An empty aluminum pan was used as the reference. The standard heating rate used was $10{ }^{\circ} \mathrm{C} / \mathrm{min}$, The temperature range of the scan was from -50 to $150{ }^{\circ} \mathrm{C}$. 


\section{Methylation of CDPA chain transfer agent}

A solution of CDPA $(5.00 \mathrm{~g}, 12.40 \mathrm{mmol})$ in anhydrous dichloromethane $(10 \mathrm{~mL})$ was introduced in a dry flask containing anhydrous methanol $(0.79 \mathrm{~g}, 24.80 \mathrm{mmol})$. Then a solution of DCC (5.11 g, $24.80 \mathrm{mmol})$ and DMAP $(0.30 \mathrm{~g}, 2.48 \mathrm{mmol})$ in anhydrous DCM (20 mL) was added dropwise to the reaction mixture at $0{ }^{\circ} \mathrm{C}$. The esterification reaction proceeded with stirring at room temperature for $24 \mathrm{~h}$. The product was further purified by a silica chromatography $\left(\mathrm{CH}_{2} \mathrm{Cl}_{2}: n\right.$-hexane $=1: 3$ ), and finally dried at $45^{\circ} \mathrm{C}$ under vacuum to obtain an orange oil.

\section{Synthesis of PPEGMA10.4- CDPA-Me}

PEGMA (24.0 g, $0.048 \mathrm{~mol})$, Me-CDPA (1.67 g, $4.00 \mathrm{mmol})$, AIBN (0.13 g, $0.80 \mathrm{mmol})$, 1,3,5-trioxacyclohexane $(0.43 \mathrm{~g}, 4.80 \mathrm{mmol})$, and 1,4-dioxane $(24.00 \mathrm{~g})$ were weighed into a $100 \mathrm{~mL}$ round bottom flask and purged with nitrogen for $45 \mathrm{~min}$. The flask was then immersed into a preheated oil bath at $70{ }^{\circ} \mathrm{C}$ for $4 \mathrm{~h}$ (Monomer conversion $=86.6 \%$ as judged by ${ }^{1} \mathrm{H}$ NMR). The polymerization was then quenched by immersion in ice water and exposure to air. The product was precipitated with excess $n$-hexane $(300 \mathrm{~mL})$ and washed several times with additional $n$-hexane. The precipitated product was then dried at $45{ }^{\circ} \mathrm{C}$ under vacuum overnight. The polymer was analyzed by THF GPC with $M_{\mathrm{n}}=6.5 \mathrm{~kg} / \mathrm{mol}$ and $M_{\mathrm{w}} / M_{\mathrm{n}}=1.12$ as determined by reference to polystyrene standards. Other PPEGMA -CDPA-Me macro-RAFT agents were synthesized in the same way.

\section{Redox initiated RAFT-mediated emulsion polymerization}

A typical protocol for RAFT-mediated emulsion polymerization of GlyMA at $20 \% \mathrm{w} / \mathrm{w}$ monomer feeding with a target DP of 150 is given as follows: PPEGMA $10.4-\mathrm{CDPA}-\mathrm{Me}(0.16 \mathrm{~g}, 0.028$ mmol), GlyMA (0.60 g, $4.22 \mathrm{mmol})$ were weighed into a $10 \mathrm{~mL}$ round bottom flask. Then a certain amount of water (2.24 $\mathrm{g}$ in this case) was added into the flask to dissolve all reagents. The reaction mixture was degassed with nitrogen at $25{ }^{\circ} \mathrm{C}$ for $20 \mathrm{~min}$ before immersion into a preheated water bath at $50{ }^{\circ} \mathrm{C}$. After the temperature was stabilized, degassed solutions of KPS $(150 \mu \mathrm{L}, 10 \mathrm{mg} / \mathrm{mL}$ $5.628 \mu \mathrm{mol})$ and $\mathrm{NaAs}(11 \mu \mathrm{L}, 100 \mathrm{mg} / \mathrm{mL} 5.628 \mu \mathrm{mol})$ (the molar ratio of [NaAs]:[KPS]:[PPEGMA 10.4-CDPA-Me] $=0.2: 0.2: 1)$ were injected in that order via microsyringes. The polymerization was allowed to continue under protection of nitrogen for $2 \mathrm{~h}$ to ensure full monomer conversion. The polymerization was quenched by exposure to air and the addition of a 
small amount of hydroquinone. All RAFT-mediated emulsion polymerizations were conducted in the same way.

\section{Kinetics of redox initiated RAFT-mediated emulsion polymerization at different temperatures}

A typical protocol for RAFT-mediated emulsion polymerization of GlyMA at $20 \% \mathrm{w} / \mathrm{w}$ monomer feeding with a target DP of 150 is given as follows: PPEGMA $10.4-\mathrm{CDPA}-\mathrm{Me}(0.40 \mathrm{~g}, 0.070$ mmol), GlyMA (1.50 g, $10.55 \mathrm{mmol})$, and 1,3,5-trioxacyclohexane (0.095 g, $1.06 \mathrm{mmol})$ were weighed into a $10 \mathrm{~mL}$ round bottom flask. Then a certain amount of water (5.60 $\mathrm{g}$ in this case) was added into the flask to dissolve all reagents. The solution was degassed with nitrogen at $25^{\circ} \mathrm{C}$ for 20 min before immersion into a preheated water bath at $50{ }^{\circ} \mathrm{C}$. After the temperature was stabilized, degassed solutions of KPS $(380 \mu \mathrm{L}, 10 \mathrm{mg} / \mathrm{mL} 14.07 \mu \mathrm{mol})$ and NaAs $(28 \mu \mathrm{L}, 100 \mathrm{mg} / \mathrm{mL} 14.07$ $\mu \mathrm{mol}$ ) (the molar ratio of [NaAs]:[KPS]:[PPEGMA $10.4-\mathrm{CDPA}-\mathrm{Me}]=0.2: 0.2: 1$ ) were injected in that order via microsyringes. Samples were withdrawn at predetermined time intervals by syringes under nitrogen, and the polymerization was quenched by exposure to air and the addition of a small amount of hydroquinone. The samples were then analyzed by ${ }^{1} \mathrm{H}$ NMR spectroscopy and GPC.

5. Redox initiated RAFT-mediated emulsion polymerization of PPEGMA15.1-P(GlyMA100-co-EDGMA2)

A typical protocol for RAFT-mediated emulsion polymerization of PPEGMA $_{15.1}$-P(GlyMA $100-c o-$ EDGMA $\left._{2}\right)$ : GlyMA (0.80 g, $\left.5.63 \mathrm{mmol}\right), \operatorname{EGDMA}(0.022 \mathrm{~g}, 0.11$ mmol), and PPEGMA 15.1 -CDPA-Me $(0.45 \mathrm{~g}, 0.056 \mathrm{mmol})$ were weighed into a $10 \mathrm{~mL}$ round bottom flask. Then a certain amount of water ( $2.97 \mathrm{~g}$ in this case) was added into the flask to dissolve all reagents. The reaction mixture was degassed with nitrogen at $25{ }^{\circ} \mathrm{C}$ for 20 min before immersion into a preheated water bath at $50{ }^{\circ} \mathrm{C}$. After the temperature was stabilized, degassed solutions of KPS (300 $\mu \mathrm{L}, 10 \mathrm{mg} / \mathrm{mL} 11 \mu \mathrm{mol})$ and NaAs $(22 \mu \mathrm{L}, 100 \mathrm{mg} / \mathrm{mL} 11 \mu \mathrm{mol})$ (the molar ratio of $\left.[\mathrm{NaAs}]:[\mathrm{KPS}]:\left[\mathrm{PPEGMA}_{15.1}-\mathrm{CDPA}-\mathrm{Me}\right]=0.2: 0.2: 1\right)$ were injected in that order via microsyringes. The polymerization was allowed to continue under protection of nitrogen for $2 \mathrm{~h}$ to ensure full monomer conversion. The polymerization was quenched by exposure to air and the addition of a small amount of hydroquinone. 


\section{ADDITIONAL RESULTS}
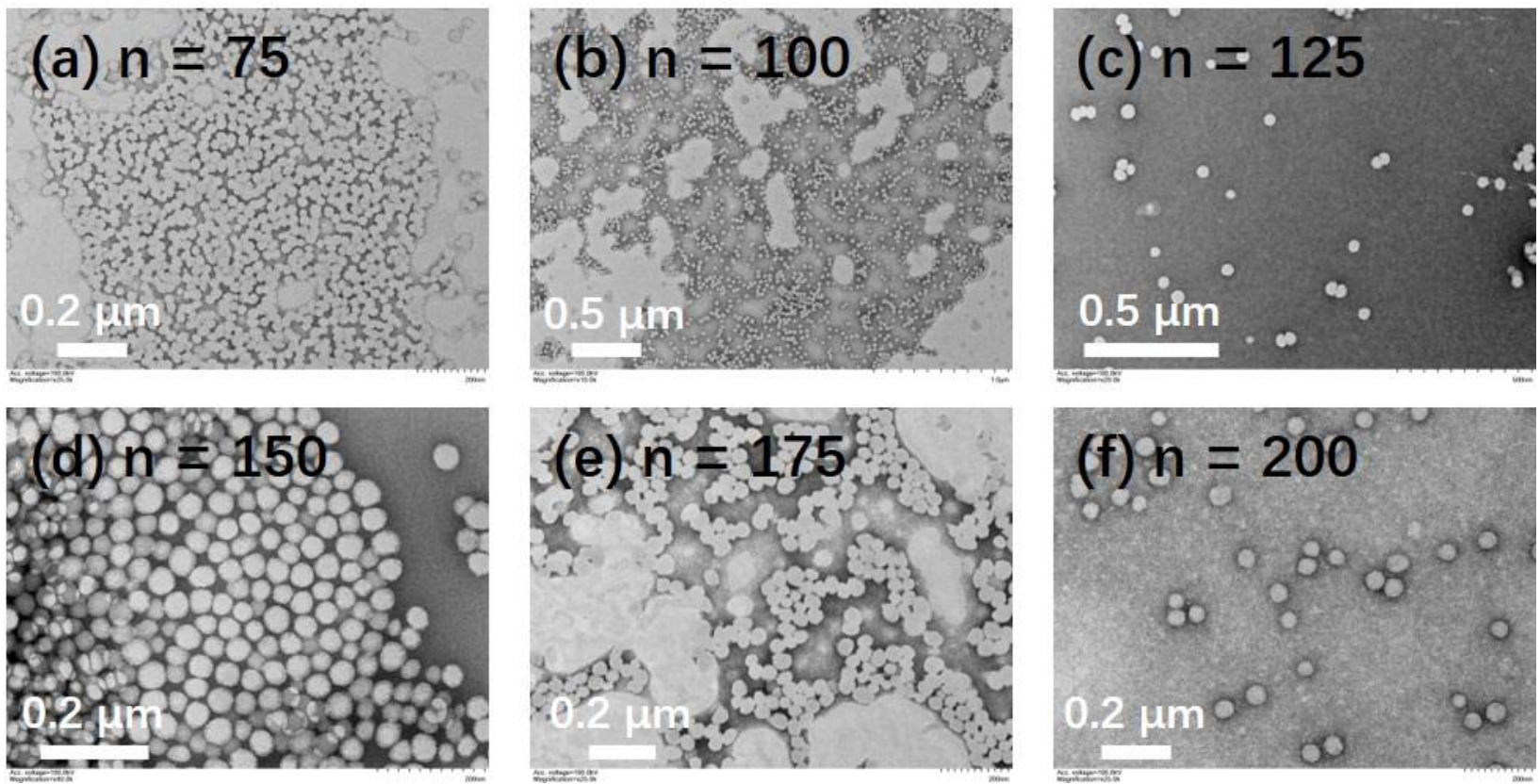

Figure S1. TEM images of PPEGMA $10.4-\mathrm{PGlyMA}_{n}$ diblock copolymer nano-objects prepared by RAFT-mediated emulsion polymerization of GlyMA $(20 \% \quad \mathrm{w} / \mathrm{w})$ at $25 \quad{ }^{\circ} \mathrm{C}$ using

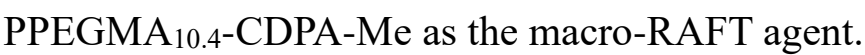
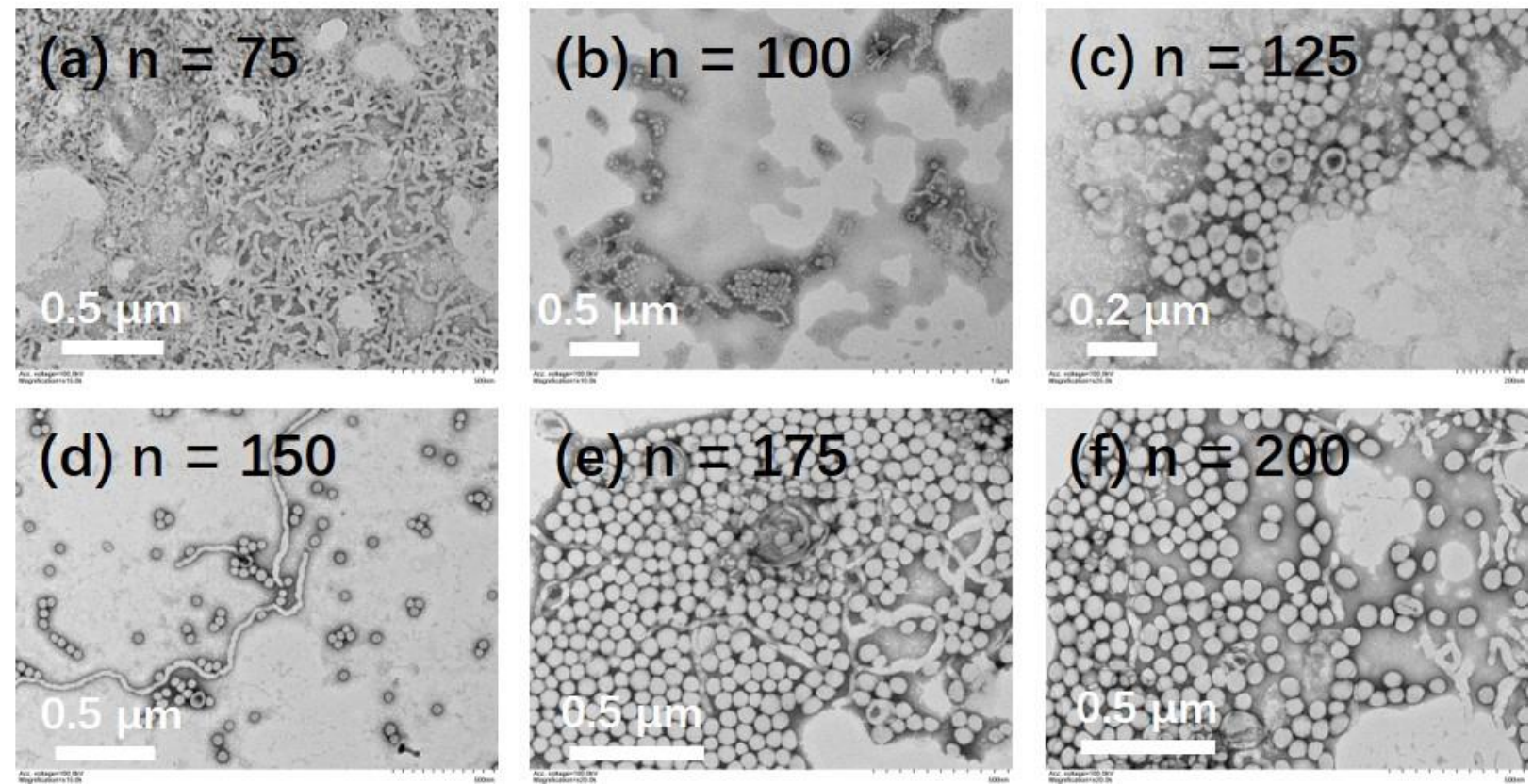

Figure S2. TEM images of PPEGMA $10.4-P_{1}$ SlyMA $_{n}$ diblock copolymer nano-objects prepared by RAFT-mediated emulsion polymerization of GlyMA $(20 \% \quad \mathrm{w} / \mathrm{w})$ at $37 \quad{ }^{\circ} \mathrm{C}$ using PPEGMA $10.4-\mathrm{CDPA}-\mathrm{Me}$ as the macro-RAFT agent. 

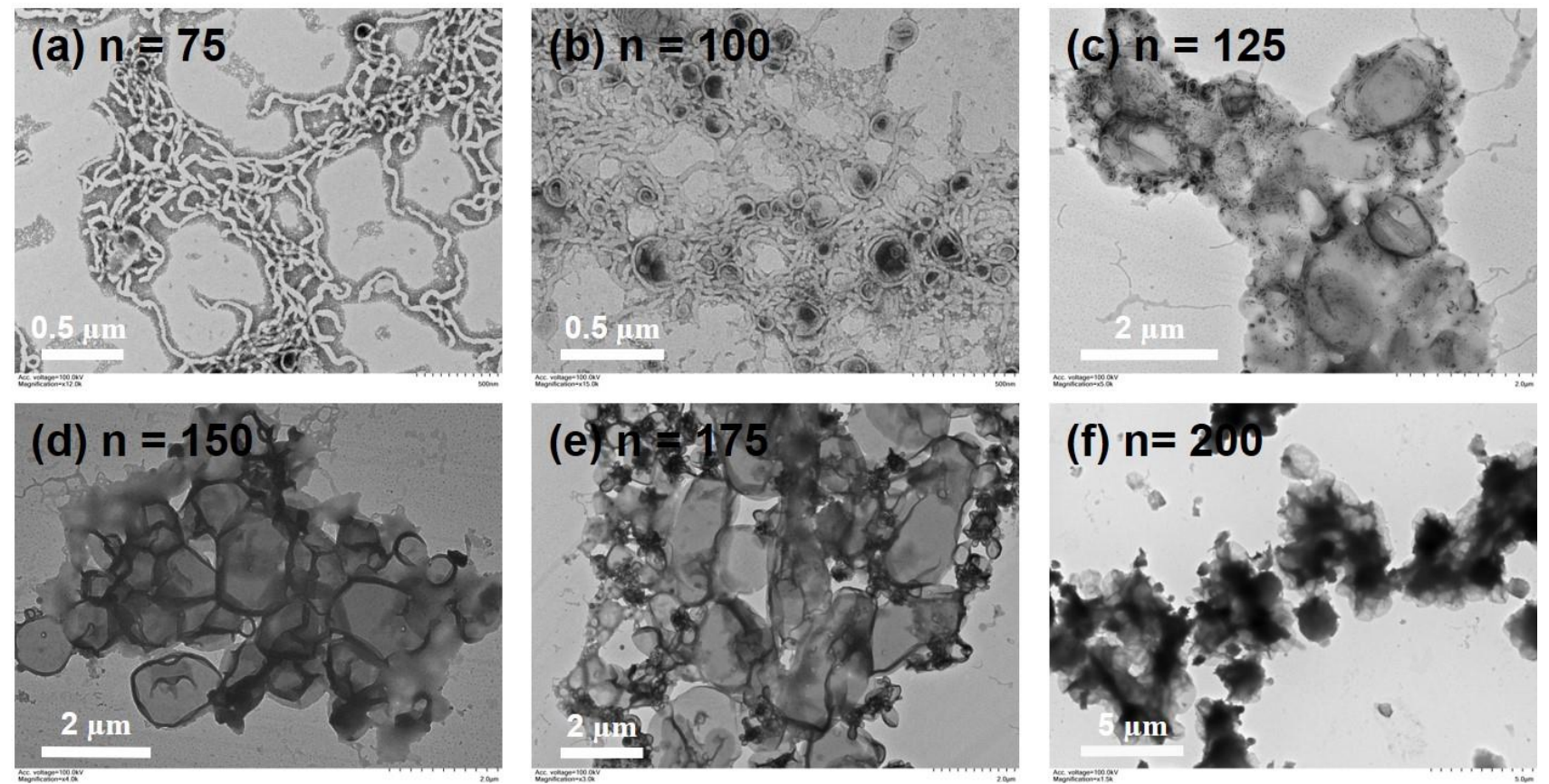

Figure S3. TEM images of PPEGMA $10.4-\mathrm{PGlyMA}_{\mathrm{n}}$ diblock copolymer nano-objects prepared by RAFT-mediated emulsion polymerization of GlyMA $(10 \% \quad \mathrm{w} / \mathrm{w})$ at $50 \quad{ }^{\circ} \mathrm{C}$ using

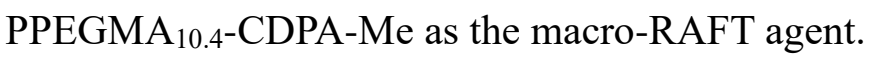
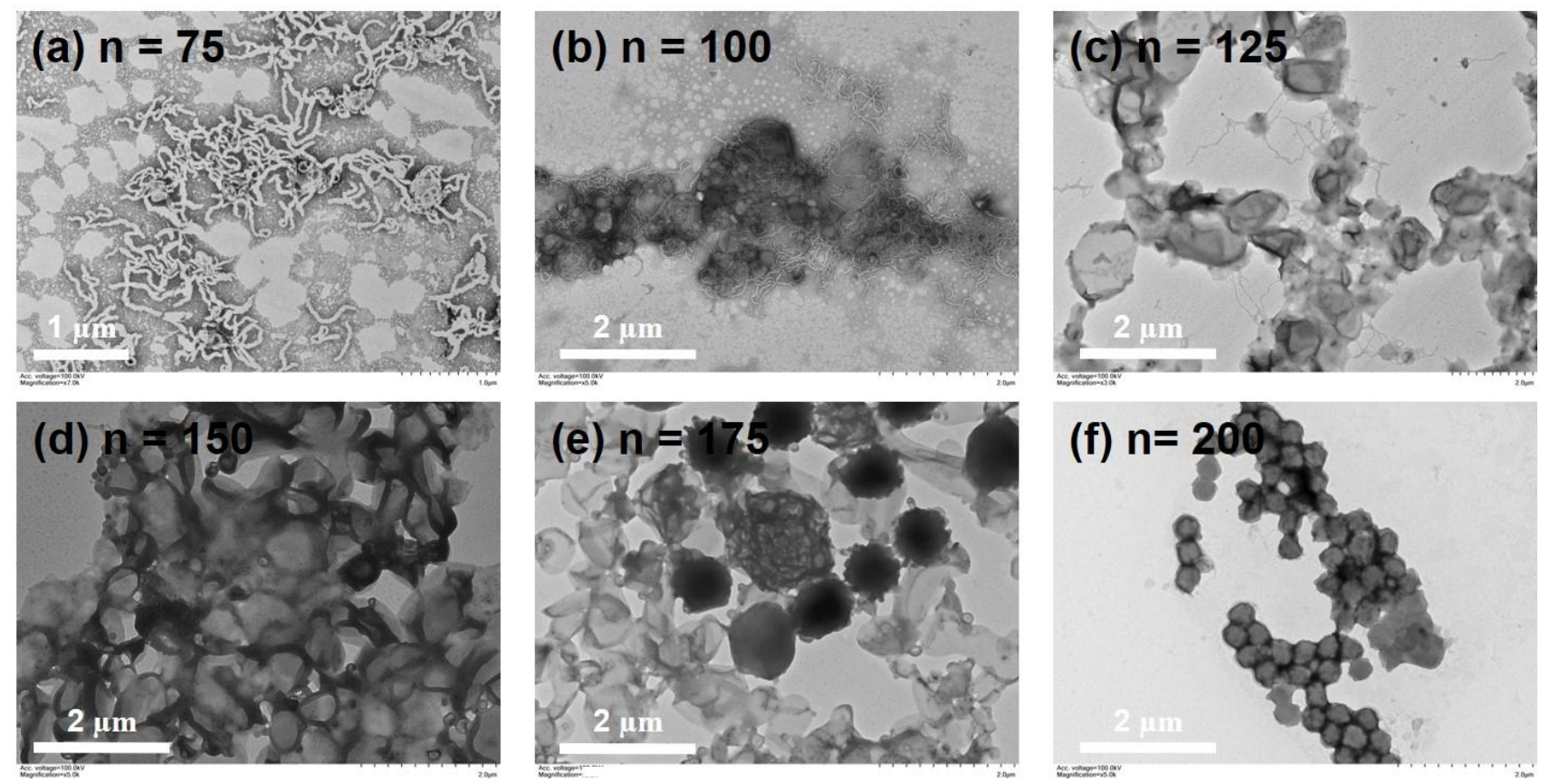

Figure S4. TEM images of PPEGMA $10.4-P_{\text {GlyMA }}$ diblock copolymer nano-objects prepared by RAFT-mediated emulsion polymerization of GlyMA $(15 \% \quad \mathrm{w} / \mathrm{w})$ at $50 \quad{ }^{\circ} \mathrm{C} \quad$ using PPEGMA $_{10.4-C D P A-M e}$ as the macro-RAFT agent. 


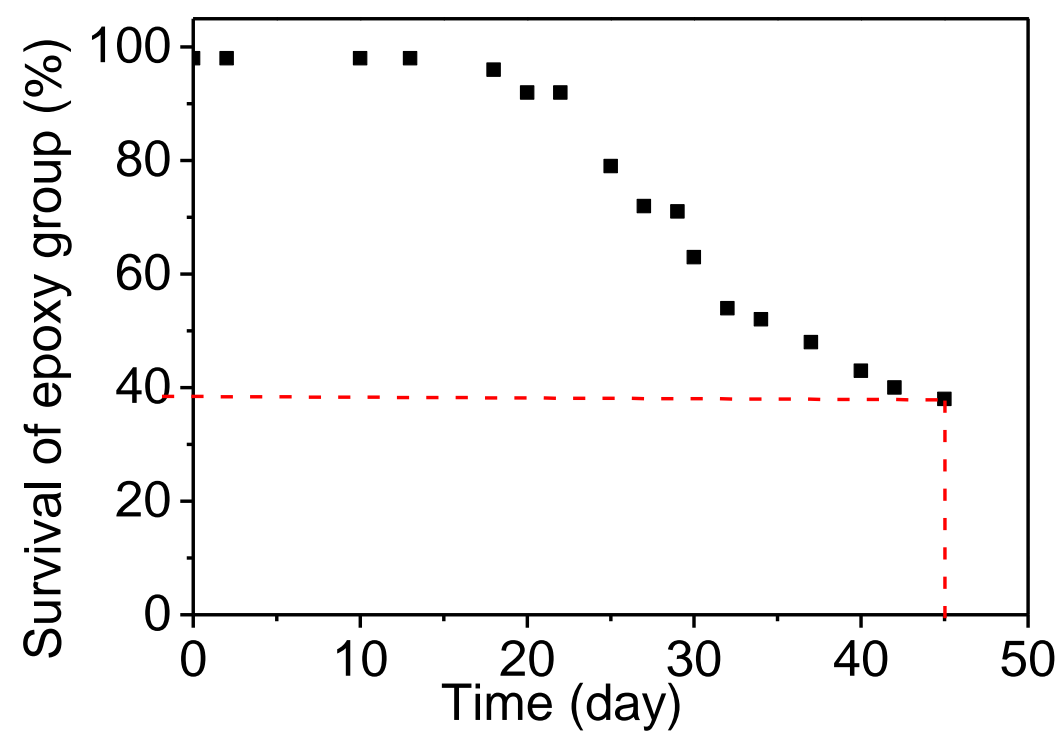

Figure S5. Survival of epoxy group for the PPEGMA $10.4-\mathrm{PGlyMA}_{150}$ vesicles in water at room temperature.

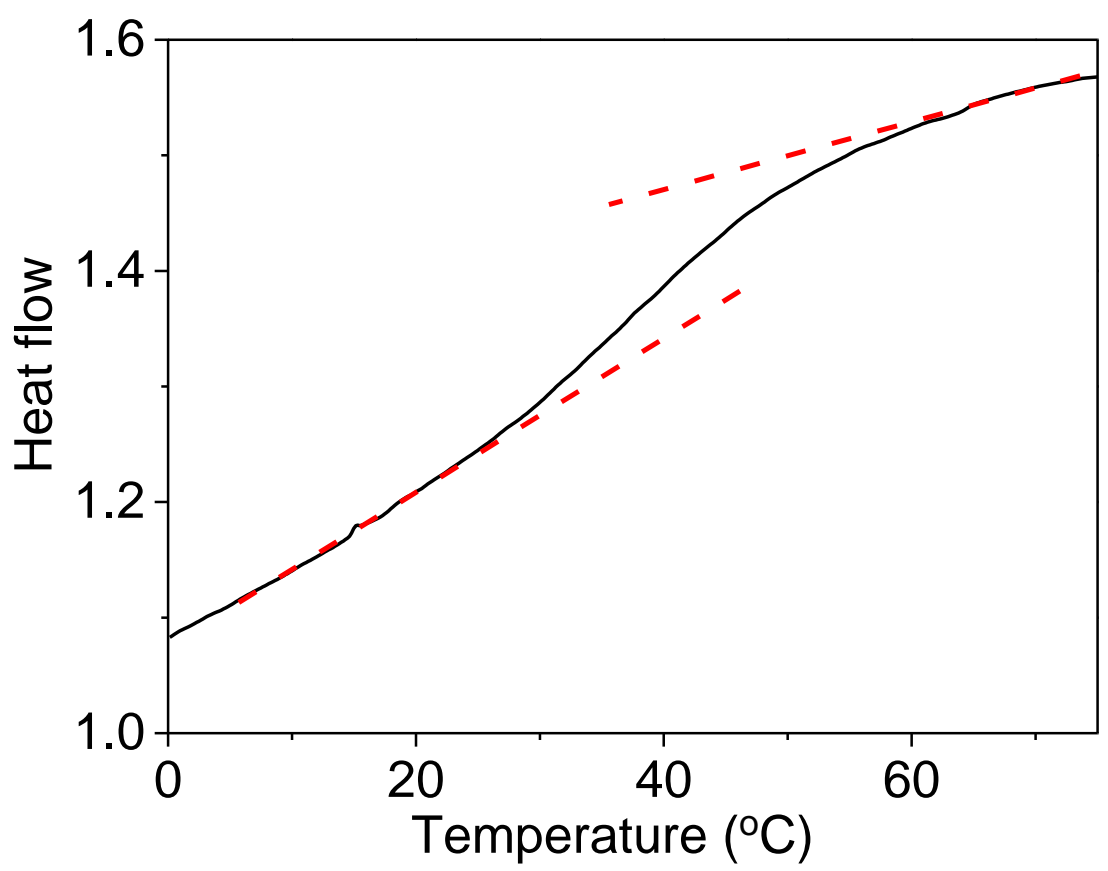

Figure S6. DSC heating thermogram for PGlyMA68-CDPA prepared by RAFT solution polymerization in DMF. The added dash lines represent baselines before and after glass transition. 
Table S1. GPC data of PPEGMA4.8-PMMA ${ }_{n}$ and PPEGMA4.8-PBzMA $n$ diblock copolymers prepared by RAFT-mediated emulsion polymerization at $50^{\circ} \mathrm{C}$ using PPEGMA4.8-CDPA-Me.

\begin{tabular}{|c|c|c|c|c|}
\hline Entry number & Target composition & $\begin{array}{c}\text { Monomer } \\
\text { conversion }\end{array}$ & $M_{\mathrm{n}}(\mathrm{kg} / \mathrm{mol})$ & $M_{\mathrm{w}} / M_{\mathrm{n}}$ \\
\hline 1 & PPEGMA $_{4.8}-$ PMMA $_{50}$ & $>99 \%$ & 7.4 & 1.23 \\
\hline 2 & PPEGMA $_{4.8}-$ PMMA $_{75}$ & $>99 \%$ & 7.5 & 1.23 \\
\hline 3 & PPEGMA $_{4.8}-$ PMMA $_{100}$ & $>99 \%$ & 8.1 & 1.18 \\
\hline 4 & PPEGMA $_{4.8}-$ PBzMA $_{50}$ & $>99 \%$ & 16.7 & 1.50 \\
\hline 5 & PPEGMA $_{4.8}-$ PBzMA $_{75}$ & $>99 \%$ & 18.6 & 1.64 \\
\hline 6 & PPEGMA $_{4.8}-$ PBzMA $_{100}$ & $>99 \%$ & 27.5 & 2.43 \\
\hline
\end{tabular}

\section{REFERENCE}

[1] Shen, W, et al. Biocompatible, Antifouling, and Thermosensitive Core-Shell Nanogels Synthesized by RAFT Aqueous Dispersion Polymerization. Macromolecules, 2011, 44(8): p. 2524-2530. 